\title{
The suppression of TRIM21 and the accumulation of IFN- $\alpha$ play crucial roles in the pathogenesis of osteonecrosis of the femoral head
}

\author{
Kenji Tateda ${ }^{1,2}$, Shunichiro Okazaki ${ }^{1,2}$, Satoshi Nagoya ${ }^{2}$, Ryuichi Katada ${ }^{1}$, Keisuke Mizuo ${ }^{1}$, Satoshi Watanabe ${ }^{1}$, \\ Toshihiko Yamashita ${ }^{2}$ and Hiroshi Matsumoto ${ }^{1}$
}

Osteonecrosis of the femoral head (ONFH), the pathogenesis of which remains unclear, has been observed in autoimmune disease patients treated with corticosteroids. Recently, it has been shown that anti-tripartite motif-containing 21 (TRIM21) autoantibodies, which are often present in patients with systemic lupus erythematosis and Sjögren's syndrome, inhibit the E3 ligase activity of TRIM21. TRIM21 negatively regulates nuclear factor- $\kappa B$ (NF- $\kappa$ B) and interferon regulatory factors (IRFs) 3 and 7, three downstream transcription factors, via toll-like receptor 4 signaling. The aim of this study was to clarify the role of TRIM21 in the pathogenesis of ONFH using an animal model. Male Wistar rats were injected with lipopolysaccharide (LPS) twice and with methylprednisolone (MPSL) or saline three times. $N$-acetyl cysteine (NAC) was administered either concurrently with MPSL or once daily for the 3 days following the last MPSL injection. The incidence of ONFH in the MPSL group was $23.5 \%$. Co-treatment of NAC and MPSL increased the incidence of ONFH to $55.6 \%$. MPSL treatment decreased the activity of NF- $\kappa$ B in the liver and significantly increased the activity of both IRF3 and IRF7. No significant differences were observed in the activity of any of these three transcription factors between the MPSL and the co-treatment groups. In the femoral head, co-treatment with NAC and MPSL significantly decreased the expression of TRIM21 at $3 \mathrm{~h}$ and significantly increased the expression of interferon (IFN)- $\alpha$ at $24 \mathrm{~h}$ when compared with the MPSL group. IFN- $\alpha$ is known to induce cell death. These findings suggest that the suppression of TRIM21 in the femoral head causes an accumulation of IFN- $\alpha$, which in turn leads to the development of ONFH. In conclusion, the suppression of TRIM21 resulting from altered NF- $\kappa \mathrm{B}$ and IRF homeostasis accelerates the ONFH in rats treated with corticosteroids following LPS administration.

Laboratory Investigation (2012) 92, 1318-1329; doi:10.1038/labinvest.2012.89; published online 23 July 2012

KEYWORDS: femoral head; IFN- $\alpha$; NF- $\kappa$ B; osteonecrosis; TRIM21; Viperin

Osteonecrosis of the femoral head (ONFH) often leads to a progressive collapse of the femoral head followed by degenerative arthritis of the hip joint, which results in decreased quality of life for patients. Non-traumatic ONFH has been observed after corticosteroid therapy in middle-aged patients with autoimmune diseases, such as systemic lupus erythematosis (SLE). ${ }^{1,2}$ However, the pathogenesis of ONFH remains unclear, and there are no known preventative treatments for ONFH.

Recent studies have suggested that the innate immune system may be associated with the pathogenesis of autoimmune diseases. The translocation of toll-like receptor 7
(TLR7) has been shown to accelerate systemic autoimmunity, ${ }^{3}$ and the deletion of TLR7 is known to decrease serum levels of IgG and to prevent lymphocyte activation in the lymph node and spleen in a murine model of SLE. ${ }^{4}$ Therefore, it has been hypothesized that the innate immune system may contribute to the pathogenesis of autoimmune diseases, especially SLE. In patients with SLE, circulating interferon (IFN) $\alpha$ levels are frequently elevated. ${ }^{5}$ Lipopolysaccharide (LPS) has been shown to exacerbate disease symptoms in a murine model of SLE. ${ }^{6}$ Anti-tripartite motifcontaining 21 (TRIM21; also known as Ro52) autoantibodies have often been observed in patients with SLE and Sjögren's

\footnotetext{
${ }^{1}$ Department of Legal Medicine and Molecular Alcohology, Sapporo Medical University School of Medicine, Sapporo, Japan and ${ }^{2}$ Department of Orthopedic Surgery, Sapporo Medical University School of Medicine, Sapporo, Japan

Correspondence: Professor H Matsumoto, MD, PhD, Department of Legal Medicine and Molecular Alcohology, Sapporo Medical University School of Medicine, S-1 W-17, Sapporo 060-8556, Japan.

E-mail: hmatsumo@sapmed.ac.jp

Received 14 February 2012; revised 23 March 2012; accepted 4 April 2012
} 
syndrome $e^{7,8}$ and are known to inhibit the E3 ligase activity of TRIM21. ${ }^{9}$ TRIM21 inhibits the activation of nuclear factor$\kappa \mathrm{B}(\mathrm{NF}-\kappa \mathrm{B})$, a downstream transcription factor, via TLR4 and TLR7 signaling. ${ }^{10}$ In addition, TRIM21 negatively regulates downstream transcription factors, that is, IFN regulatory factors (IRFs) 3 and 7, via promoting the ubiquitinproteasome-mediated degradation of IRF3 and IRF7, which limits IFN- $\alpha$ production. ${ }^{11}$ In contrast, corticosteroid treatment is known to induce steatosis of the liver and bone marrow. Recently, the IFN-inducible antiviral protein, Viperin, has been shown to promote TLR7- and TLR9mediated production of type I IFN by plasmacytoid dendritic cells (pDCs). ${ }^{12}$ Therefore, we hypothesized that corticosteroid treatment inhibits NF- $\kappa$ B but does not inhibit IFN $-\alpha$ release via IRF7, resulting in an imbalance between NF- $\kappa \mathrm{B}$ and IRF activation, which causes ONFH. Especially, accumulating $\mathrm{NF}-\kappa \mathrm{B}$ inhibition under corticosteroid treatment, that is, co-treatment of an antioxidant may cause osteonecrosis.

In this study, we examined ONFH in the rat following treatment with corticosteroids following LPS injections and found that co-treatment with $\mathrm{N}$-acetyl cysteine (NAC), an antioxidant, and corticosteroids resulted in increased osteonecrosis. We then examined the changes in NF- $\kappa \mathrm{B}$, IRF3, and IRF7 activation and the changes in the expression of TRIM21, IFN- $\alpha$, and CD45R in the femoral head after treatment.

\section{MATERIALS AND METHODS Animals}

All experiments were performed in accordance with the guidelines of the Ministry of Sports, Culture, Science and Technology of Japan. All procedures were approved by the Animal Experimental Committee of the Sapporo Medical University (Approval No. 09-008). Male Wistar rats (10 weeks old) were obtained from the Sankyo Lab Service (Sapporo, Japan), housed in a temperature- and humiditycontrolled room with unlimited access to food and water and maintained on a 12-h light/dark cycle.

\section{Experimental Protocols}

The animals were administered $2 \mathrm{mg} / \mathrm{kg}$ LPS (from Escherichia coli serotype 055: B5; Sigma-Aldrich, LLC, St Louis, MO, USA) intravenously two times. Twenty $\mathrm{mg} / \mathrm{kg}$ methylprednisolone (MPSL) or saline was administered intramuscularly three times at 24-h intervals after the last LPS injection (the saline or MPSL group, respectively). ${ }^{13}$ In all, $100 \mathrm{mg} / \mathrm{kg}$ NAC was administered intraperitoneally three times, either concurrently with each MPSL injection (the MPSL + NAC group) or once daily on the 3 days following the last MPSL injection (the NAC after MPSL group). The femur, liver, and spleen were harvested, and blood was collected from the inferior vena cava at various time points after the last MPSL treatment (ie, $3 \mathrm{~h}, 12 \mathrm{~h}, 24 \mathrm{~h}, 1$ week, and 2 weeks). Blood was centrifuged immediately, and the supernatant was stored as platelet-rich plasma at $-84^{\circ} \mathrm{C}$ until further analysis.

\section{Fractionation of Nuclear Extracts}

Nuclear proteins in the liver and spleen were fractionated as described previously. ${ }^{14} \mathrm{In}$ all, $500 \mathrm{mg}$ liver samples or $100 \mathrm{mg}$ spleen samples were homogenized on ice in $2.5 \mathrm{ml}$ TKM buffer ( $50 \mathrm{mM}$ Tris-HCl, pH 7.5, $25 \mathrm{mM} \mathrm{KCl}, 0.32 \mathrm{M}$ sucrose, $5 \mathrm{mM} \mathrm{MgCl} 2,1 \mathrm{mM}$ DTT, $1 \mathrm{mM}$ PMSF, and $1 \mathrm{mM} \mathrm{Na}_{3} \mathrm{VO}_{4}$ ). The homogenate was centrifuged at $600 \times g$ for $10 \mathrm{~min}$. The pellet was resuspended in $2.5 \mathrm{ml} 2 \mathrm{M}$ sucrose-TKM buffer and centrifuged at $40000 \times g$ for $2 \mathrm{~h}$. Pellets containing the nuclear fraction were resuspended in $20 \mu \mathrm{l}$ cold buffer A (10 mM HEPES, $2 \mathrm{mM} \mathrm{MgCl} 2,0.1 \mathrm{mM}$ EDTA, 10\% [v/v] glycerol, $1 \mathrm{mM}$ DTT, and $0.5 \mathrm{mM}$ PMSF) for $20 \mathrm{~min}$ on ice and centrifuged at $15000 \times g$ for $30 \mathrm{~s}$. Pellets were then resuspended in $200 \mu \mathrm{l}$ cold buffer B (50 mM HEPES, $50 \mathrm{mM}$ $\mathrm{KCl}, 300 \mathrm{mM} \mathrm{NaCl}, 0.1 \mathrm{mM}$ EDTA, $10 \%$ [v/v] glycerol, $1 \mathrm{mM}$ DTT, and $0.5 \mathrm{mM}$ PMSF) for $20 \mathrm{~min}$ on ice and centrifuged at $15000 \times g$ for $5 \mathrm{~min}$. Supernatants were collected, and protein concentrations were determined using a BCATM protein assay kit (Thermo Fisher Scientific, Waltham, MA, USA). Nuclear extracts were stored at $-80^{\circ} \mathrm{C}$.

\section{Electrophoresis Mobility Shift Assay}

The electrophoresis mobility shift assay (EMSA) method was performed to detect the binding activity of the transcription factors, NF- $\kappa \mathrm{B}$, IRF3, and IRF7, as described previously. ${ }^{15}$ Briefly, consensus double-stranded oligonucleotides of NF- $\kappa$ B: $5^{\prime}$-AGTTGAGGGGACTTTCCCAGGC-3', IRF3: $5^{\prime}$ GAAAGCGAAACTGAAACTGACT- $3^{\prime}$ and IRF7: $5^{\prime}$-ACTGAT CGGAACCGAACGATCTAAG- $3^{\prime}$ were end-labeled with $\left[\gamma{ }^{32} \mathrm{P}\right]$ ATP using T4 polynucleotide kinase (Boehringer Mannheim, Indianapolis, IN, USA). For binding reactions, $5 \times 10^{4}$ c.p.m. of the labeled oligonucleotide probes were incubated with $10 \mu \mathrm{g}$ nuclear extract and $1 \mu \mathrm{g}$ poly- $(\mathrm{dI}-\mathrm{dC})$ in binding buffer $(4 \%[\mathrm{v} / \mathrm{v}]$ glycerol, $1 \mathrm{mM} \mathrm{MgCl} 2,0.5 \mathrm{mM}$ EDTA, $0.5 \mathrm{mM}$ DTT, $50 \mathrm{mM} \mathrm{NaCl}, 10 \mathrm{mM}$ Tris-Cl, pH 7.5) at room temperature for $30 \mathrm{~min}$. Protein-DNA complexes were separated by electrophoresis on a $7 \%$ non-denaturing polyacrylamide gel in $0.5 \times$ TBE buffer and visualized and quantified using an Image Analyzer FLA-3000 (Fuji Photo Film, Tokyo, Japan). Quantitative analyses of each band were performed by densitometry using Quantity One 1D analysis software (Bio-Rad Laboratories, Hercules, CA, USA).

\section{Quantitative Real-Time PCR Analysis}

Total RNA was prepared with RNase-free DNase from the liver, spleen and femoral head using TRIzol reagent (Invitrogen, Tokyo, Japan) according to the manufacturer's protocol and a previous report. ${ }^{14} \mathrm{cDNA}$ was then synthesized from total RNA using SuperScriptTM III Reverse Transcriptase (Invitrogen) and oligo(dT)12-18 primers (Invitrogen). PCR primers were designed with Prime 3 software and are shown in Supplementary Table 1. Real-time RT-PCR 
amplifications were performed in volumes of $20 \mu \mathrm{l}$ containing 40 ng cDNA template with the PCR Master Mix (Takara Bio, Shiga, Japan). The PCR program involved 49 cycles of $95^{\circ} \mathrm{C}$ for $5 \mathrm{~s}$, an annealing temperature (from 53 to $62^{\circ} \mathrm{C}$ ) for $20 \mathrm{~s}$, and $72{ }^{\circ} \mathrm{C}$ for $15 \mathrm{~s}$. CypA served as the internal control in the DNA Engine Opticon Real-Time RT-PCR Detection System (MJ Research, Watertown, MA, USA). The final result for each sample was normalized to its relevant internal control value.

\section{Biochemical Analysis}

The concentrations of total cholesterol, high-density lipoprotein, triglycerides, aspartate aminotransferase (AST), alanine aminotransferase (ALT), urea nitrogen, uric acid, and creatinine in the platelet-rich plasma were measured by
SPOTCHEM D-Concept (Arkray, Tokyo, Japan) according to the manufacturer's instructions.

\section{Multiplex Cytokine Assay}

The plasma concentrations of interleukin (IL)- $1 \alpha$, IL- $1 \beta$, IL-2, IL-4, IL-6, IL-10, granulocyte macrophage colony-stimulating factor, IFN- $\gamma$, and tumor necrosis factor (TNF)- $\alpha$ were determined using the MILLIPLEX MAP Rat Cytokine/ Chemokine Panel (Millipore, Billerica, MA, USA) and the Bio-Plex Rat Cytokine 9-Plex A Panel (Bio-Rad Laboratories) in the Luminex 100 KT01 analyzer (Luminex, Austin, TX, USA) according to the manufacturer's instructions. The plasma concentration of IFN- $\alpha$ was determined using an ELISA Kit (Uscn Life Science, Wuhan, China) according to the manufacturer's instructions.

\section{a}
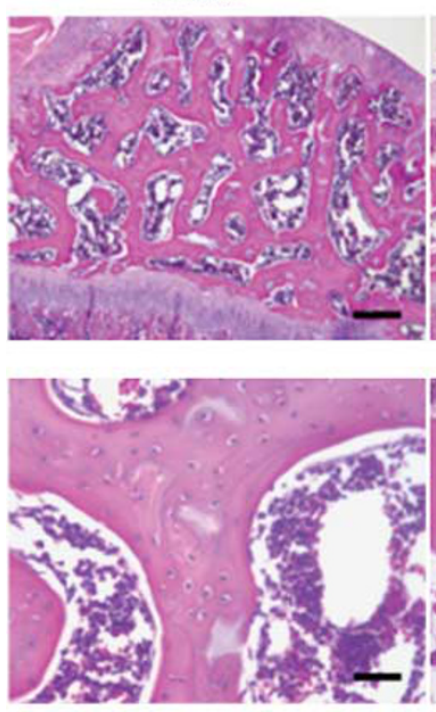

MPSL
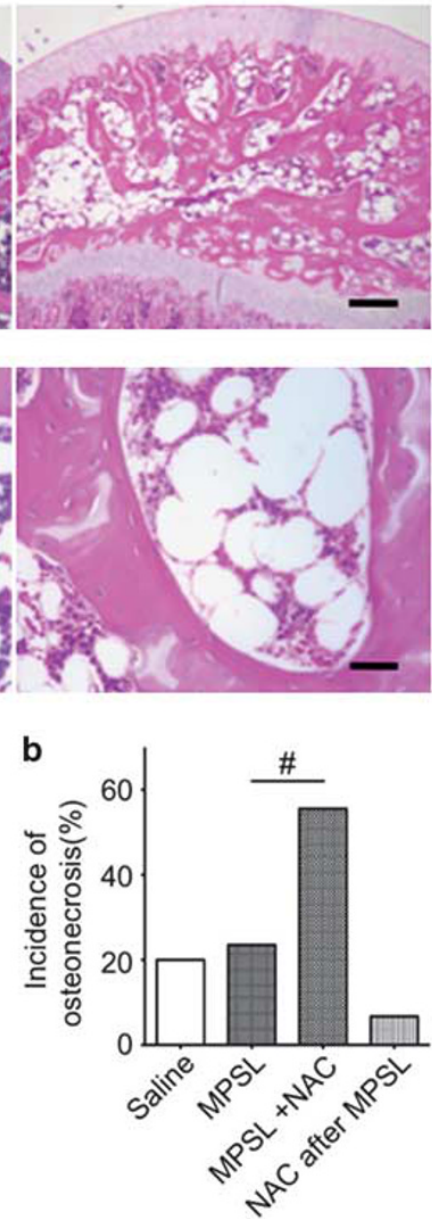

MPSL+NAC
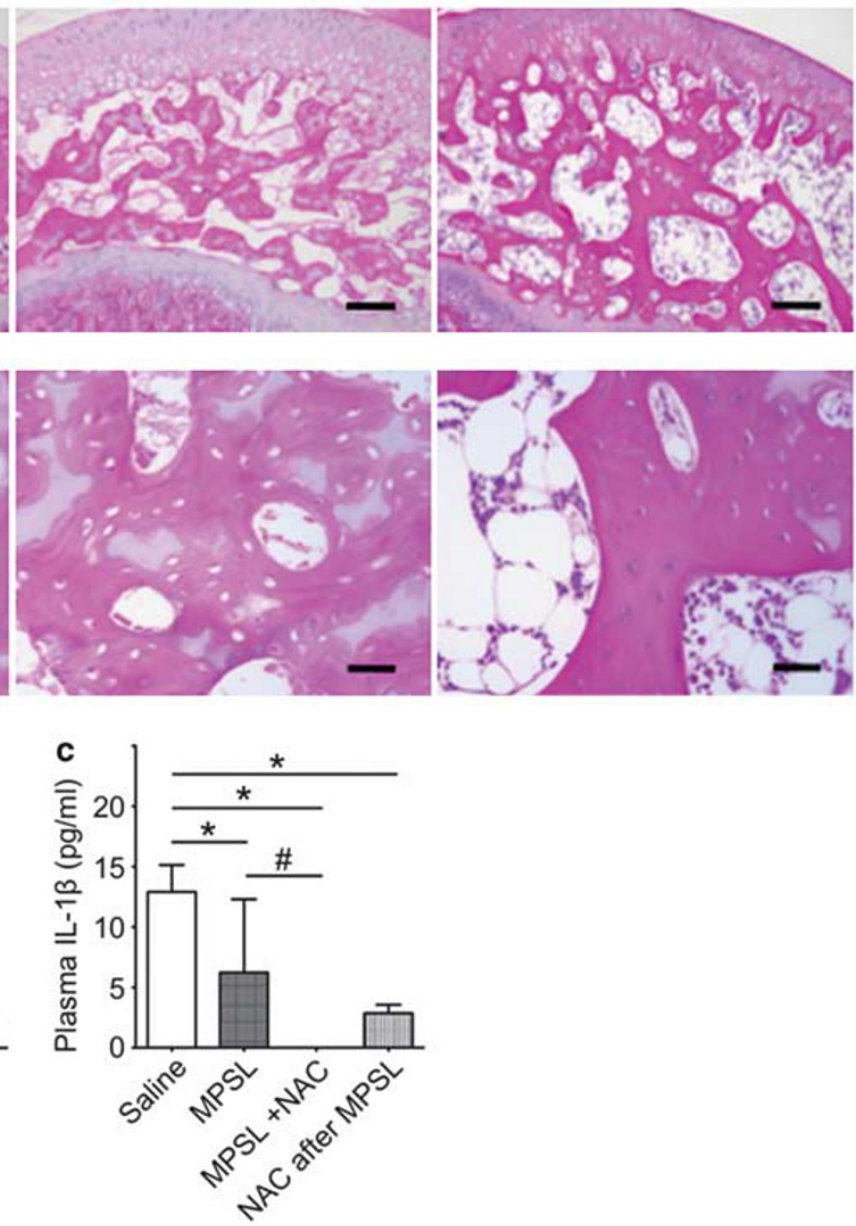

Figure 1 Co-treatment of NAC and MPSL induced ONFH. (a) Histopathological changes of the femoral head at low magnification (upper panels, scale $\mathrm{bar}=300 \mu \mathrm{m}$ ) and high magnification (lower panels, scale bar $=40 \mu \mathrm{m}$ ) by hematoxylin and eosin staining. All animals were injected twice with $2 \mathrm{mg} / \mathrm{kg}$ LPS, with a 24-h interval between injections. Saline or $20 \mathrm{mg} / \mathrm{kg}$ MPSL was administered three times after LPS injection (the saline group or the MPSL group, respectively). NAC was either administered simultaneously with MPSL (the MPSL + NAC group) or starting 1 day following the final MPSL dose (the NAC after MPSL group). (b) The incidence of ONFH in rats after their last treatment. ${ }^{*} P<0.05$ vs the MPSL group by $\chi^{2}$. (c) Plasma IL-1 $\beta$ concentrations 1 week after the last treatment are shown. Data show the mean \pm s.d. $(n=5-9) .{ }^{*} P<0.05$ vs the saline group, ${ }^{\#} P<0.05$ vs the MPSL group by one-way ANOVA with Dunnett's post hoc test. 
Table 1 Biochemical parameters 1 week after MPSL treatment

\begin{tabular}{|c|c|c|c|c|}
\hline & \multicolumn{4}{|c|}{ Treatment } \\
\hline & \multirow[t]{3}{*}{ Saline } & \multicolumn{3}{|c|}{ MPSL } \\
\hline & & & \multicolumn{2}{|c|}{ NAC } \\
\hline & & & Simultaneous & After \\
\hline$n$ & 5 & 8 & 7 & 9 \\
\hline $\begin{array}{l}\text { Total cholesterol } \\
(\mathrm{mg} / \mathrm{dl})\end{array}$ & $69.2 \pm 2.8$ & $97.3 \pm 21.9^{*}$ & $120.6 \pm 21.9^{* * * *}$ & $116.8 \pm 9.9^{*}$ \\
\hline $\mathrm{HDL}(\mathrm{mg} / \mathrm{dl})$ & $17.6 \pm 3.3$ & $39.4 \pm 14.3^{*}$ & $51.1 \pm 5.8^{*}$ & $53.1 \pm 5.8^{* * * *}$ \\
\hline $\begin{array}{l}\text { Triglyceride } \\
(\mathrm{mg} / \mathrm{dl})\end{array}$ & $33.2 \pm 7.6$ & $129.1 \pm 57.3^{*}$ & $124.0 \pm 47.4^{*}$ & $157.0 \pm 53.7^{*}$ \\
\hline AST (IU/I) & $48.0 \pm 12.2$ & $81.0 \pm 28.5^{*}$ & $66.9 \pm 29.9$ & $43.4 \pm 14.7^{* *}$ \\
\hline ALT (IU/I) & $18.4 \pm 3.1$ & $54.1 \pm 25.5^{*}$ & $41.6 \pm 20.0$ & $27.6 \pm 10.4^{* *}$ \\
\hline
\end{tabular}

Data show mean \pm s.d. ${ }^{*} P<0.05$ vs saline group. ${ }^{*} P<0.05$ vs MPSL group by one-way ANOVA with Dunnett's post hoc test.

\section{Histopathology and Immunohistochemistry}

Femur, liver, spleen, and kidney samples were fixed with $10 \%$ formalin in $0.1 \mathrm{M}$ phosphate buffer, $\mathrm{pH}$ 7.4. Bone samples were decalcified with Kalkitox solution (Wako, Osaka, Japan) and then neutralized with sodium sulfate buffer. Tissues were embedded in paraffin, and $2-\mu \mathrm{m}$ sections were processed using routine hematoxylin and eosin staining protocols to assess the general architecture and injury status of the tissue. For immunohistochemistry, sections were deparaffinized and irradiated at $750 \mathrm{~W}$ in a microwave oven in $10 \mathrm{mM}$ sodium citrate buffer, $\mathrm{pH}$ 6.0. Sections were then treated with $3 \%$ hydrogen peroxide to inhibit endogenous peroxidases. After washing in TBS with $0.025 \%$ Triton X-100, the sections were blocked with normal serum (1:10 in TBS with $1 \%$ BSA) of the species in which the secondary antibody was raised. Following blocking, sections were incubated with one of the following primary antibodies diluted in TBS containing $1 \%$ BSA: mouse monoclonal antibodies against CD45R (sc19615; 1:100; Santa Cruz Biotechnology, Santa Cruz, CA, USA), TNF receptor-associated factor (TRAF) 6 (sc-8409; 1:100; Santa Cruz Biotechnology), IFN- $\alpha$ (NBP1-42170; 1:50;

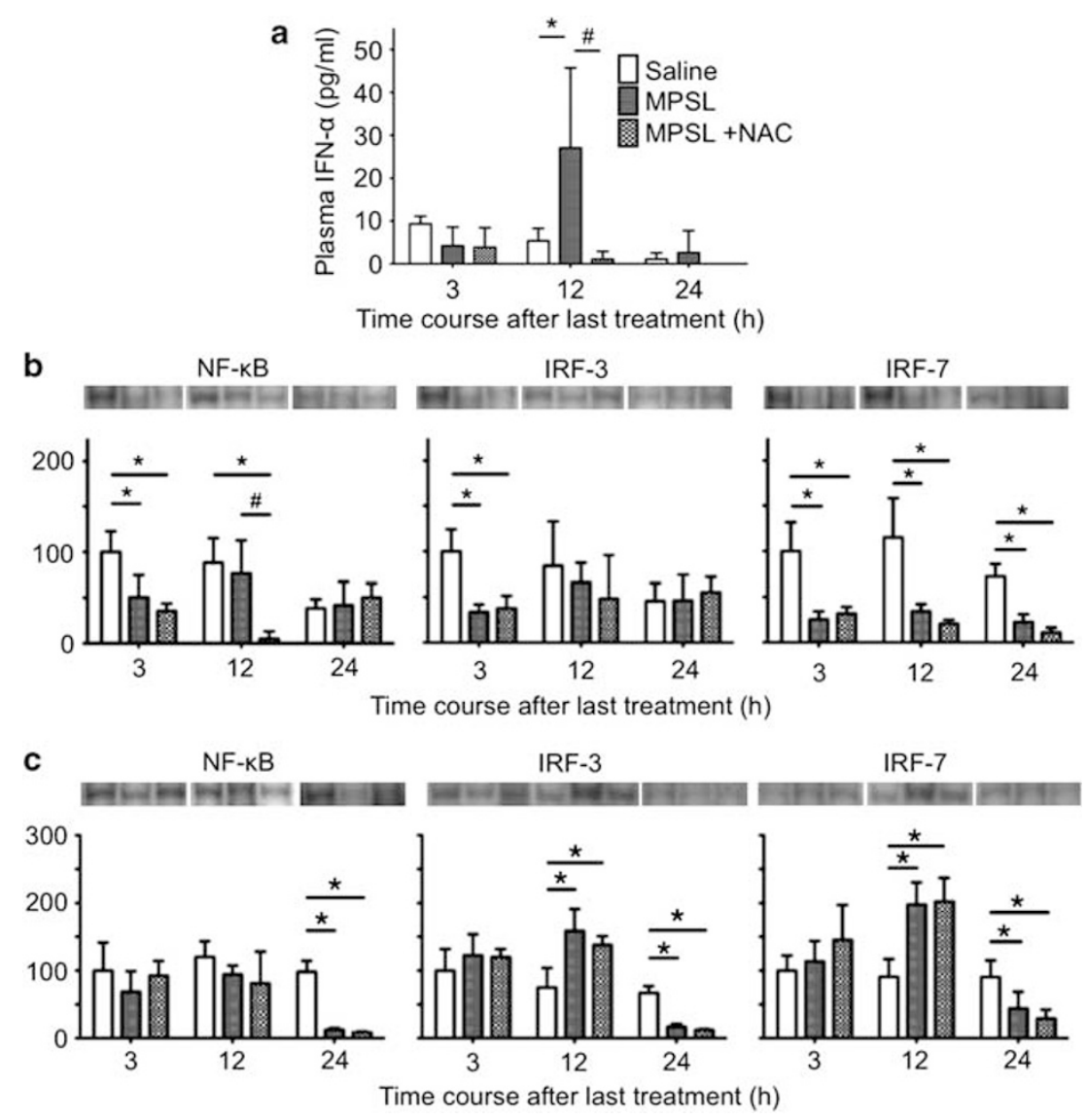

Figure 2 Immediate changes in IFN- $\alpha, \mathrm{NF}-\kappa \mathrm{B}$, and IRFs after MPSL or saline treatments in the rat. (a) The plasma concentration of IFN- $\alpha$ at 3,12 , and $24 \mathrm{~h}$ after the last treatment is shown. Data show the mean \pm s.d. $(n=3-4) .{ }^{\star} P<0.05$ vs the saline group, ${ }^{\#} P<0.05$ vs the MPSL group by two-way ANOVA with Bonferroni's post hoc test. (b) The activities of NF- $\kappa$ B, IRF3, and IRF7 in the spleen were detected by EMSA 3, 12, and $24 \mathrm{~h}$ after the last treatment. Data show the mean \pm s.d. $(n=3-4)$. ${ }^{*} P<0.05$ vs the saline group, ${ }^{\#} P<0.05$ vs the MPSL group by two-way ANOVA with Bonferroni's post hoc test. (c) The activities of $\mathrm{NF}-\kappa \mathrm{B}, \mathrm{IRF} 3$, and IRF7 in the liver were detected by EMSA 3, 12, and $24 \mathrm{~h}$ after the last treatment. Data show the mean \pm s.d. $(n=3-4)$. ${ }^{*} P<0.05 v s$ the saline group by two-way ANOVA with Bonferroni's post hoc test. 
Novus Biologicals LLC, Littleton, CO, USA), rabbit polyclonal antibodies against Viperin (ab121042; 1:500; Abcam), or goat polyclonal antibody against TRIM21 (sc-21362; 1:800; Santa Cruz Biotechnology) overnight at $4{ }^{\circ} \mathrm{C}$. After washing, sections were incubated with peroxidase-labeled anti-mouse or anti-rabbit secondary antibodies, as appropriate (Histofine Simplestain Rat Max PO; Nichirei, Tokyo, Japan), for $30 \mathrm{~min}$ at room temperature. Sections that had been incubated with the goat polyclonal antibody were incubated with a biotinylated anti-goat secondary antibody (Histofine SAB-PO; Nichirei) for $10 \mathrm{~min}$ and a peroxidaselabeled streptavidin for $5 \mathrm{~min}$ at room temperature. Peroxidase activity was detected with diaminobenzidine (Histofine DAB-3S kit; Nichirei), and sections were counterstained with hematoxylin. The level of protein accumulation was estimated as the percentage of the total counterstained area that was positively stained for the protein of interest, which was determined using Image J software (NIH, Bethesda, USA).

\section{Statistical Analysis}

Data were expressed as the mean \pm s.d. Statistical analyses were performed using $\chi^{2}$ tests, one-way ANOVAs with Dunnett's post hoc tests, or two-way ANOVAs with Bonferroni's post hoc tests. Results were considered statistically significant at $P$-values $<0.05$.

\section{RESULTS}

\section{ONFH Characteristics 1 and 2 Weeks After Treatment}

We defined osteonecrosis as the diffuse presence of empty lacunae or pyknotic nuclei of osteocytes in the bone trabeculae that were accompanied by necrosis of the surrounding bone marrow cells. ${ }^{16}$ First, we investigated the incidence of ONFH after the last MPSL injection. Figure 1 shows the typical histopathological appearance of the femoral head by hematoxylin and eosin staining 1 week after the last injection of either MPSL or saline (a) and the incidence of ONFH (b). ONFH was observed in 2 of the 10 $(20 \%)$ rats in the saline group, 4 of the $17(23.5 \%)$ rats in the MPSL group and 1 of the $15(6.7 \%)$ rats in the NAC after MPSL group. However, ONFH was apparent in 10 of the $18(55.6 \%)$ rats in the MPSL + NAC group, an incidence that was significantly higher than that observed in the MPSL group. These findings suggest that co-administration of NAC with MPSL exacerbates the development of ONFH. Fat cells accumulated in the epiphysis of the femoral head in rats treated with MPSL regardless of the presence of ONFH. There were no abnormal histological appearances in liver, spleen, and kidney in all the groups (Supplementary Figure 1S). Figure 1c shows the plasma concentrations of IL- $1 \beta$ at week 1 . MPSL treatment significantly decreased the levels of IL- $1 \beta$. Indeed, the plasma levels of IL- $1 \beta$ were not detectable in the MPSL + NAC group at week 1 . These findings suggest that co-treatment of NAC with MPSL significantly suppresses the inflammatory response. The plasma concentrations of IL- $1 \alpha$, IL-2, IL-4, IL-6, IL-10, granulocyte macrophage colony-stimulating factor, IFN- $\gamma$ and TNF- $\alpha$ were below the limits of detection in all groups at week 1 . Table 1 shows the plasma concentrations of total cholesterol, high-density lipoprotein, triglyceride, AST, and ALT at week 1. MPSL treatment significantly increased the plasma lipid levels compared with saline group. This finding was in accordance with the histopathological findings of the femoral head that fat cell accumulation was observed in the rats treated with MPSL, and suggests that MPSL treatment after LPS injection caused abnormal lipid metabolism. NAC treatment with or after MPSL injection significantly increased the plasma cholesterol level. This finding suggests that NAC treatment augments abnormal lipid metabolism induced by MPSL treatment. MPSL treatment significantly increased AST and ALT. NAC treatment after MPSL injection significantly decreased these levels, but co-treatment of NAC with MPSL did not decrease these levels. Plasma urea nitrogen, uric acid, and creatinine were normal value in all the groups, in which there were no significant differences among all the groups (data not shown).

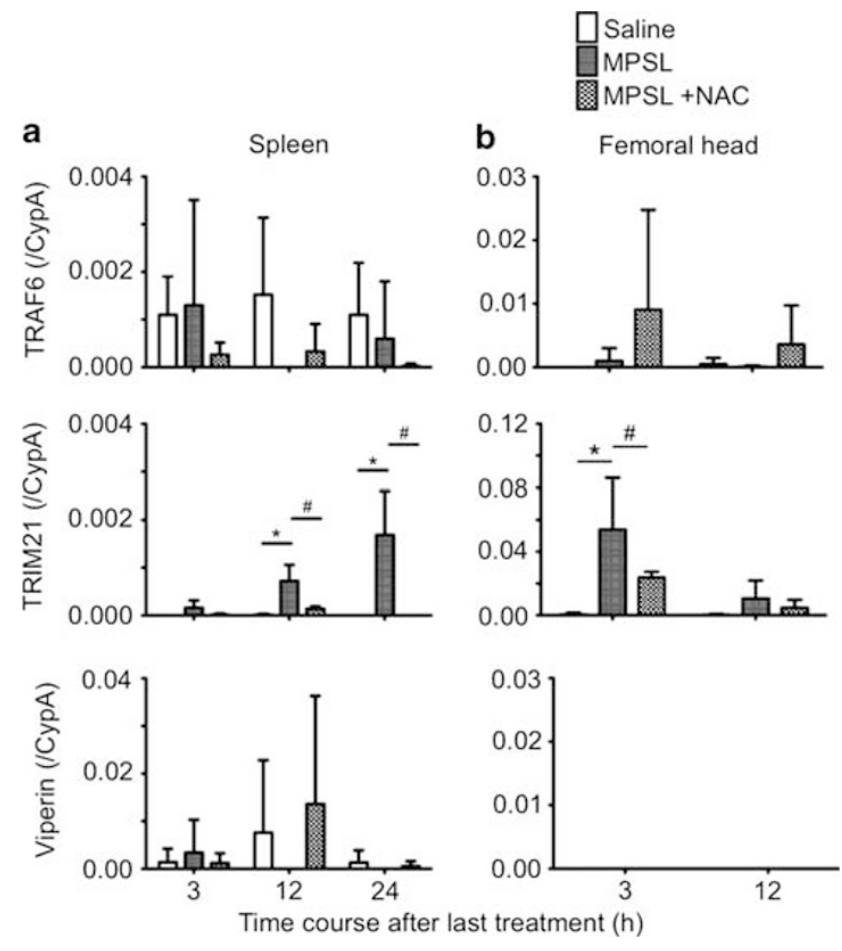

Figure 3 Immediate changes in the expression of TRAF6, TIRM21, and Viperin in the rat. The mRNA expression in the spleen (a) and femoral head (b) at 3, 12, and $24 \mathrm{~h}$ after the last treatment are shown. The amounts of these mRNA were analyzed by quantitative real-time RT-PCR using total RNA. The CypA was used as an internal control. Data show the relative fluorescence level of TRAF6, TRIM21, and Viperin to CypA as the mean \pm s.d. $(n=3-4)$. ${ }^{\star} P<0.05$ vs the saline group, ${ }^{\#} P<0.05$ vs the MPSL group by oneway ANOVA with Dunnett's post hoc test. 


\section{Pro-Inflammatory Responses After Treatment}

We hypothesized that pro-inflammatory responses immediately after treatment may contribute to the development of ONFH. Thus, we evaluated the pro-inflammatory response of rats immediately after treatment. Figure 2a shows the time course of changes in the levels of plasma IFN- $\alpha$.
IFN- $\alpha$ levels were significantly increased by MPSL treatment after $12 \mathrm{~h}$. Co-treatment of NAC with MPSL significantly decreased the IFN- $\alpha$ production induced by MPSL. We determined the activity of the transcriptional factors, NF- $\kappa \mathrm{B}$, IRF3 and IRF7, in the spleen and liver 3, 12 and $24 \mathrm{~h}$ after the last treatment. Figures $2 b$ and $c$ show the activity of NF- $\kappa$ B, a
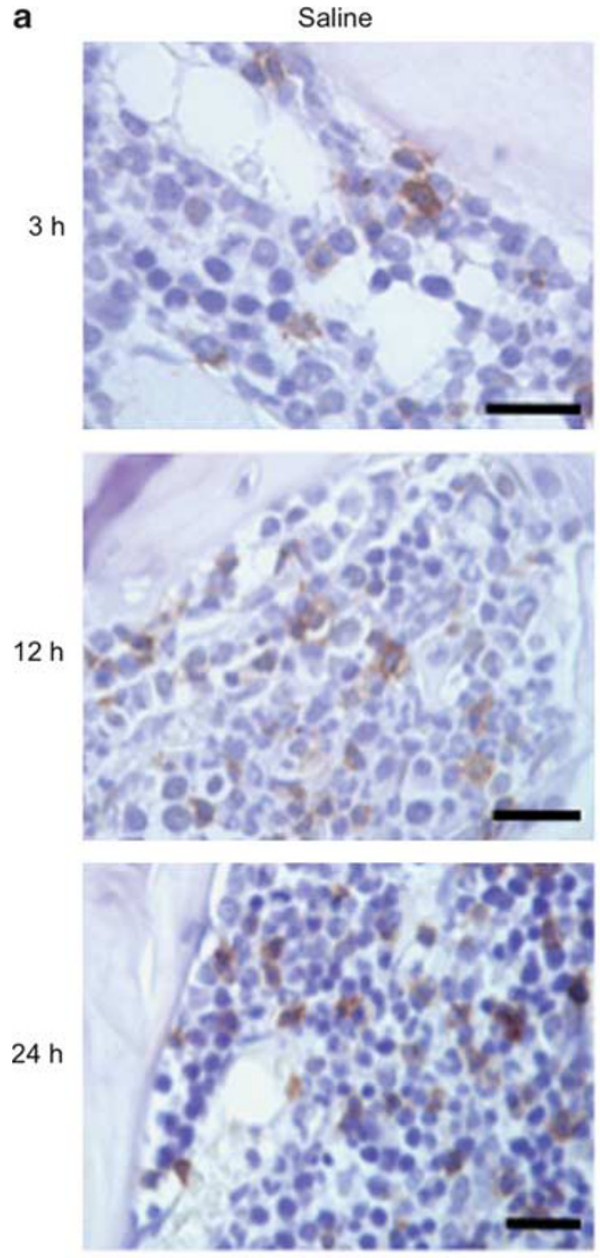

MPSL
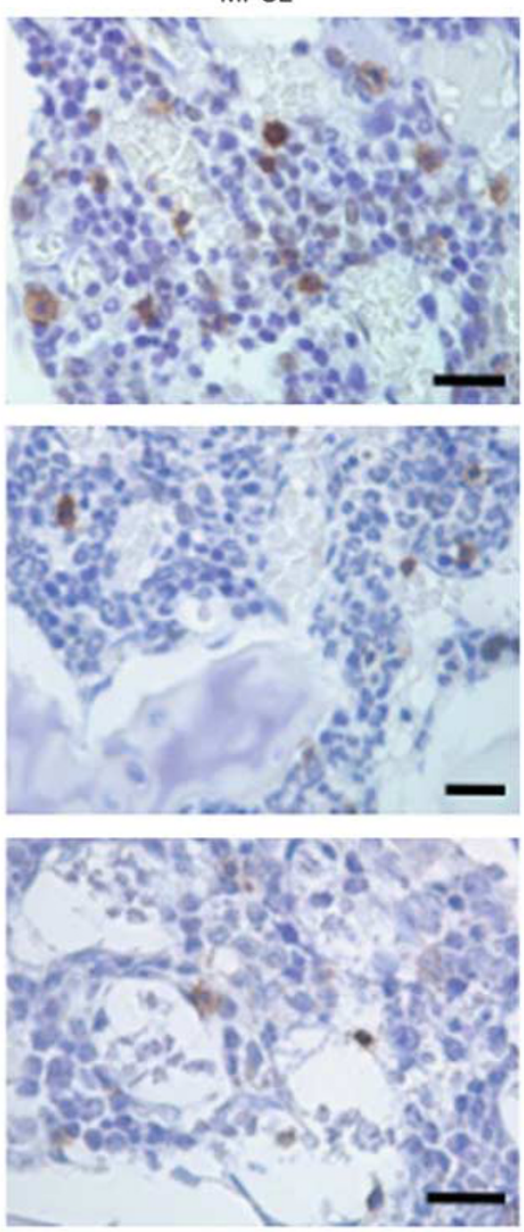

MPSL +NAC
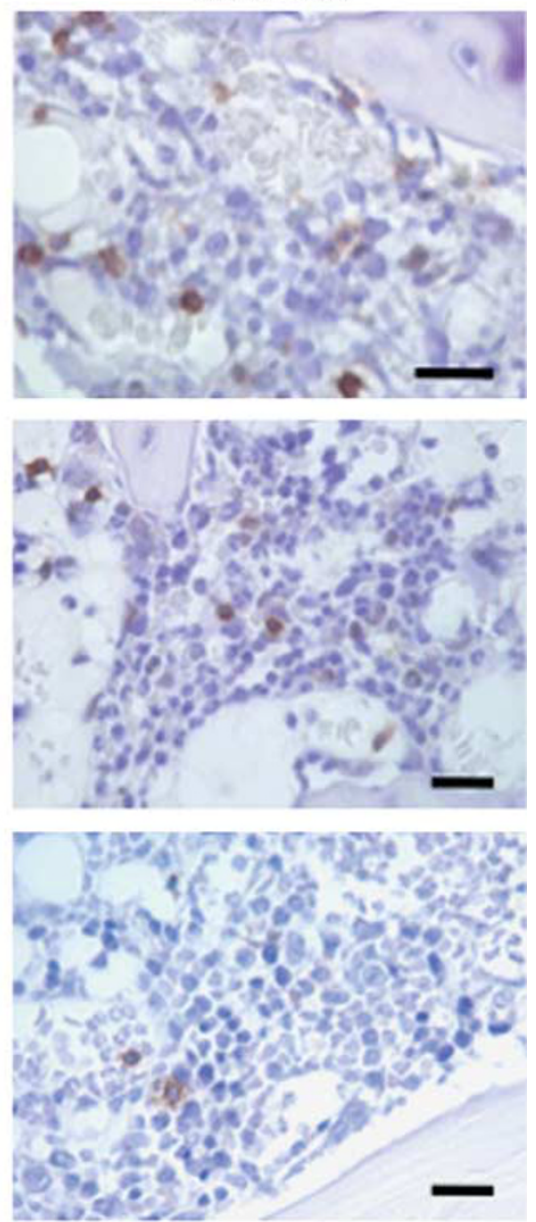

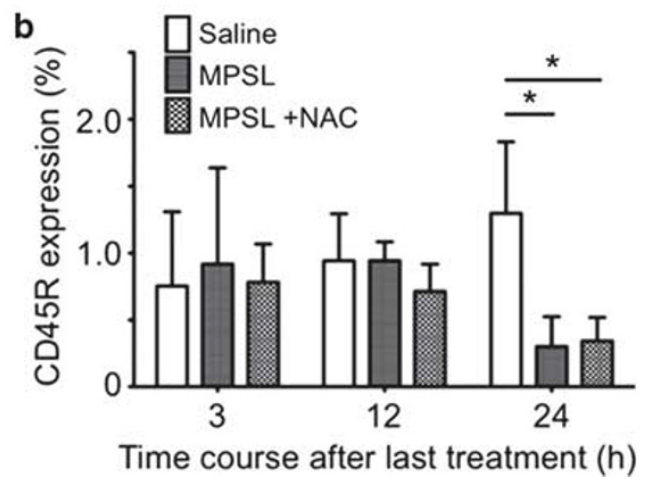

Figure 4 Immediate changes in CD45R in the femoral head. (a) Histopathological appearance of the femoral head after CD45R immunohistochemical staining 3, 12, and $24 \mathrm{~h}$ after the last treatment. Scale bar $=20 \mu \mathrm{m}$. (b) Quantitative analyses of CD45R expression in the femoral head are expressed as the percentage of the total counterstained tissue area that was stained for CD45R. Data show the mean \pm s.d. $(n=3-4)$. ${ }^{*}<0.05$ vs the saline group by two-way ANOVA with Bonferroni's post hoc test. 
IRF3, and IRF7 in the spleen and liver, respectively. MPSL treatment significantly decreased the activity of NF- $\kappa \mathrm{B}$, IRF3 and IRF7. Co-treatment of NAC with MPSL prolonged the significant inactivation of NF- $\kappa$ B for $12 \mathrm{~h}$. The activities of IRF3 and IRF7 were significantly increased by MPSL treatment in the liver at $12 \mathrm{~h}$, and then significantly decreased at $24 \mathrm{~h}$. These findings suggest that MPSL treatment after LPS injection induces the imbalance among the activity of NF- $\kappa \mathrm{B}$, IRF3 and IRF7.

\section{mRNA Expression After Treatment}

Figures $3 \mathrm{a}$ and $\mathrm{b}$ show the mRNA expression of TRAF6, TRIM21, and Viperin in the spleen and femoral head, respectively. In the MPSL group, mRNA expression of TRIM21 was significantly increased in the spleen and femoral head. Co-treatment with NAC and MPSL significantly decreased the expression of TRIM21 induced by MPSL. There were no significant differences in mRNA expressions of TRAF6 and Viperin among groups. a
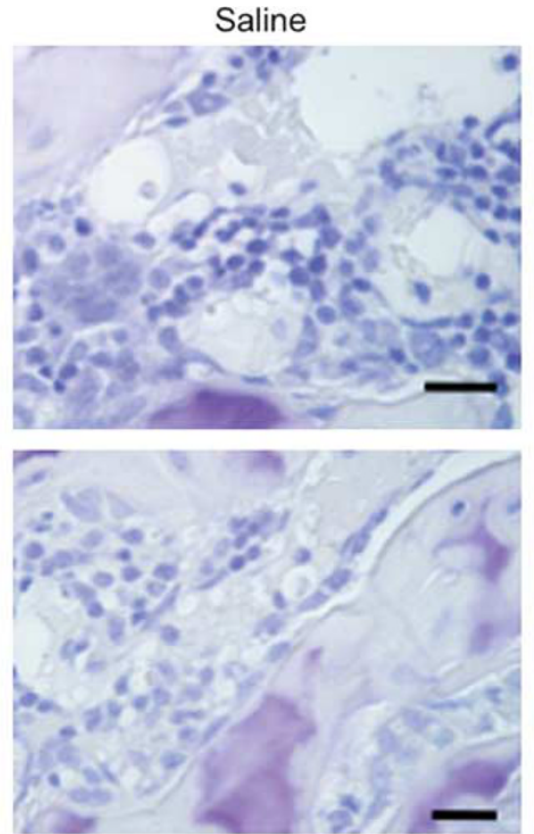

$12 \mathrm{~h}$

$24 \mathrm{~h}$

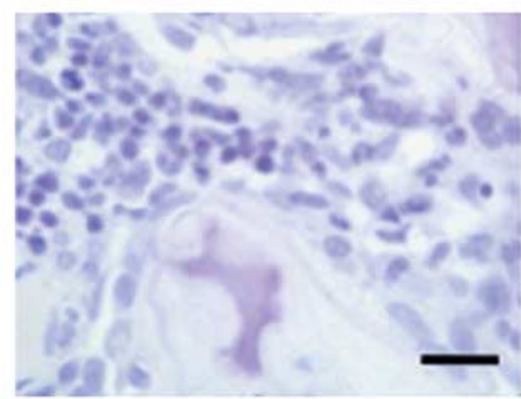

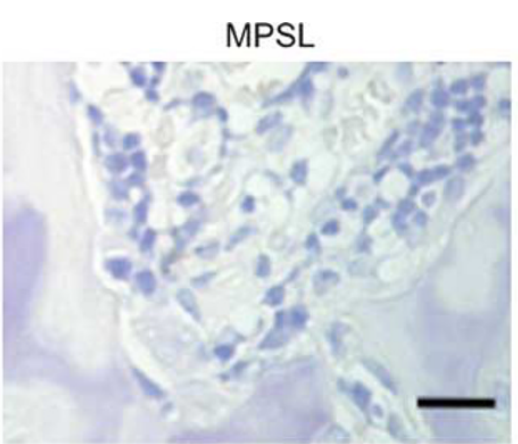
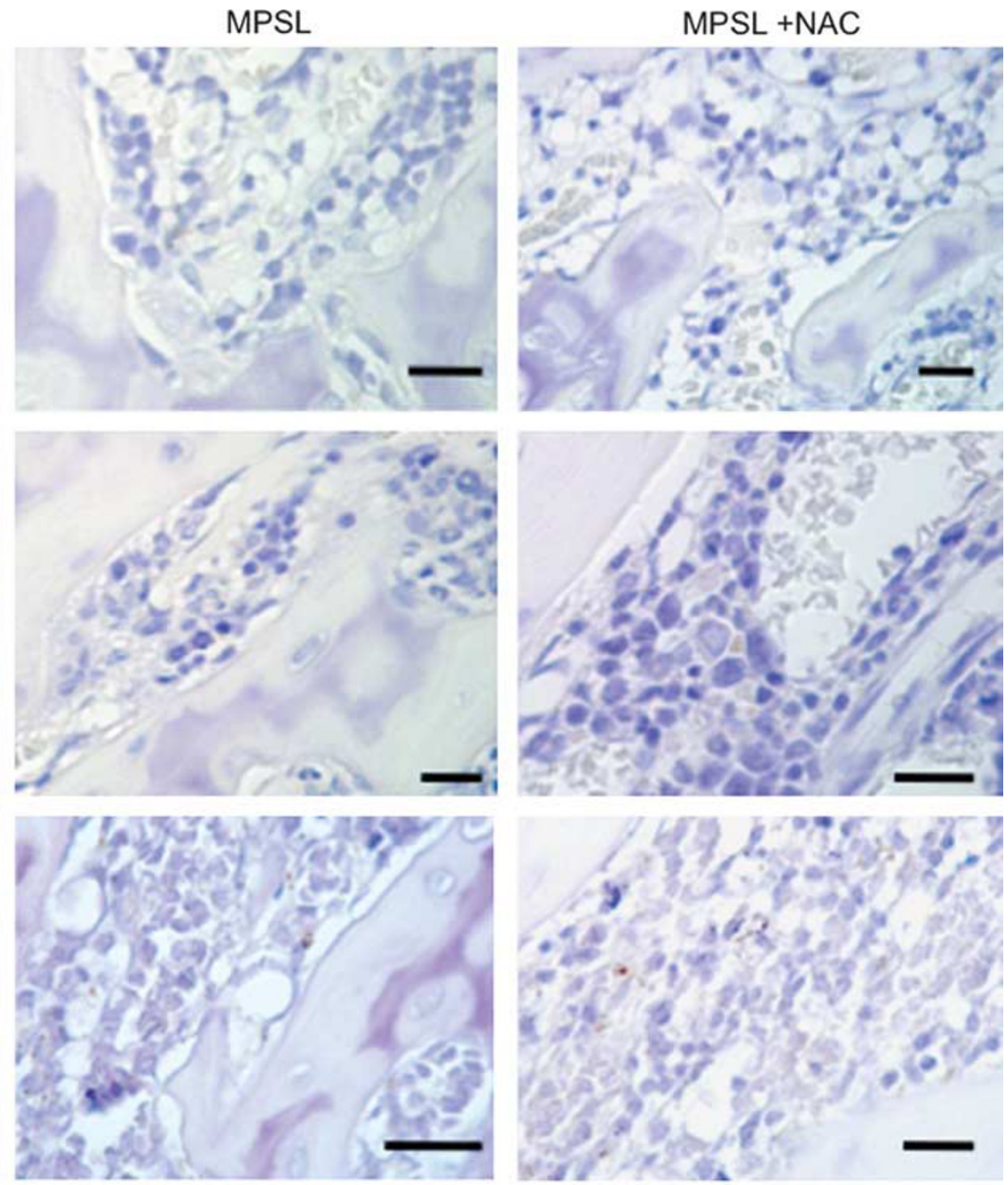

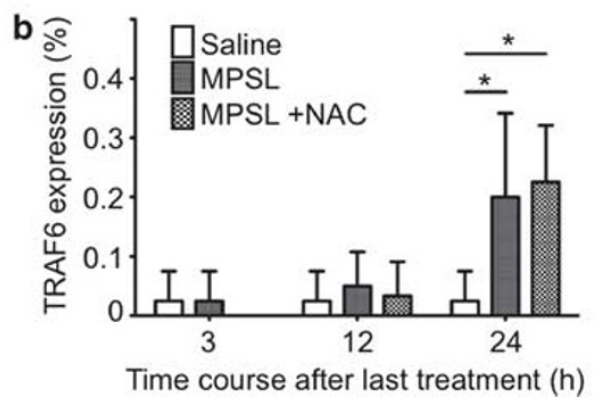

Figure 5 Immediate changes in TRAF6 in the femoral head. (a) Histopathological appearance of the femoral head after TRAF6 immunohistochemical staining 3,12, and $24 \mathrm{~h}$ after the last treatment. Scale bar $=20 \mu \mathrm{m}$. (b) Quantitative analyses of TRAF6 expression in the femoral head are expressed as the percentage of the total counterstained tissue area that was stained for TRAF6. Data show the mean \pm s.d. $(n=3-4)$. ${ }^{*}<0.05$ vs the saline group by two-way ANOVA with Bonferroni's post hoc test. 
Expression of CD45R, TRAF6, TRIM21, Viperin, and IFN- $\alpha$ in the Femoral Head After Treatment

Figures 4-8 show immunohistochemical and quantitative analyses of the expression of CD45R (Figure 4), TRAF6 (Figure 5), TRIM21 (Figure 6), Viperin (Figure 7), and IFN- $\alpha$ (Figure 8) in the femoral head. CD45R expression was readily observed on the surface of bone marrow cells at 3 and $12 \mathrm{~h}$ in all groups (Figure 4a). MPSL treatment significantly decreased the level of CD45R expression at $24 \mathrm{~h}$ (Figure 4b). These findings suggest that pDCs are abundant in the femoral head for at least $12 \mathrm{~h}$ after the last treatment in all groups. TRAF6 expression was observed in bone marrow cells in the MPSL group and the MPSL + NAC group at $24 \mathrm{~h}$ (Figure 5a). MPSL treatment significantly increased the expression of TRAF6 (Figure 5b). TRIM21 expression was observed in osteoblasts and bone marrow cells (Figure 6a) a
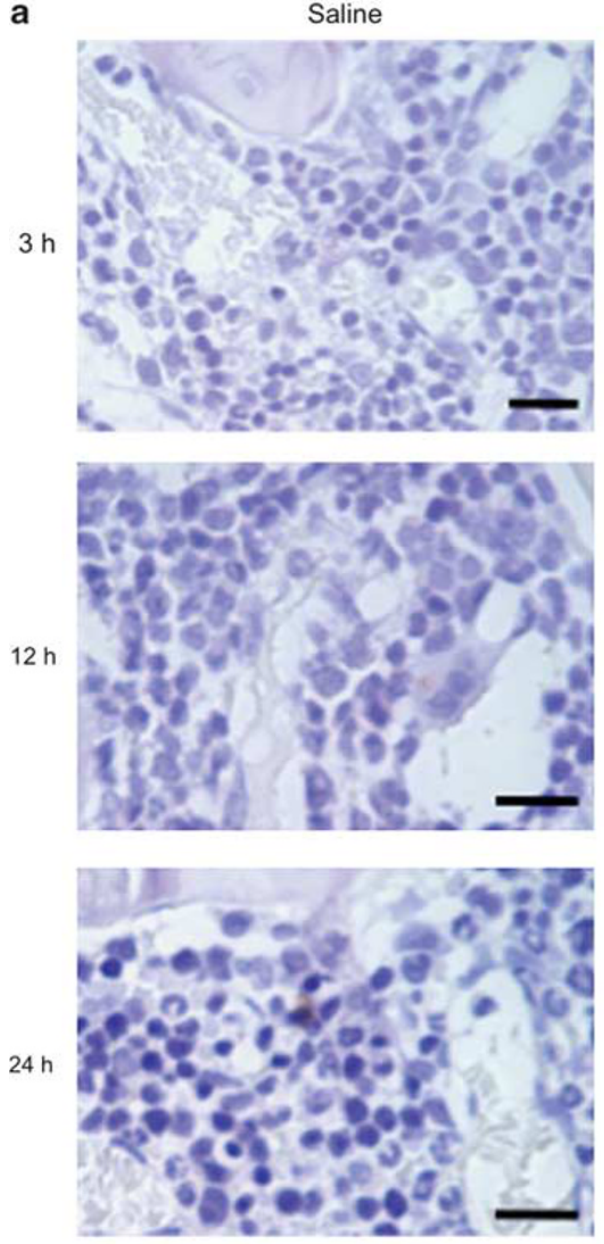

MPSL
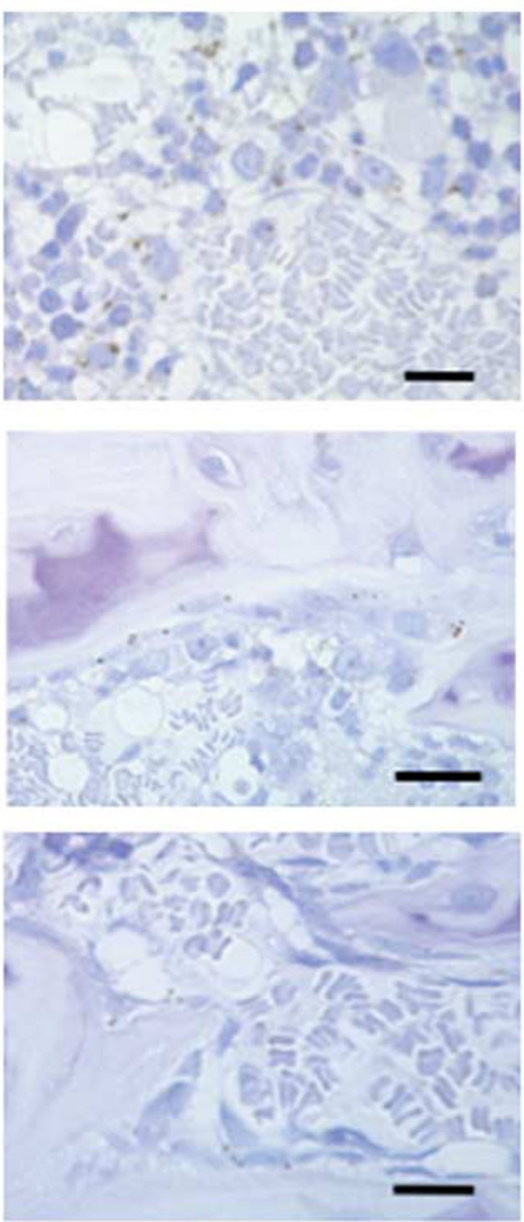

b

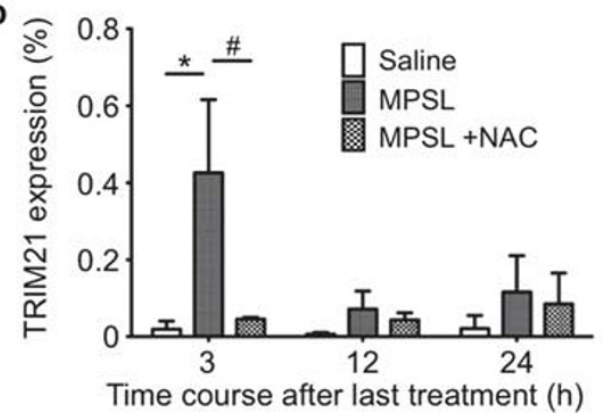

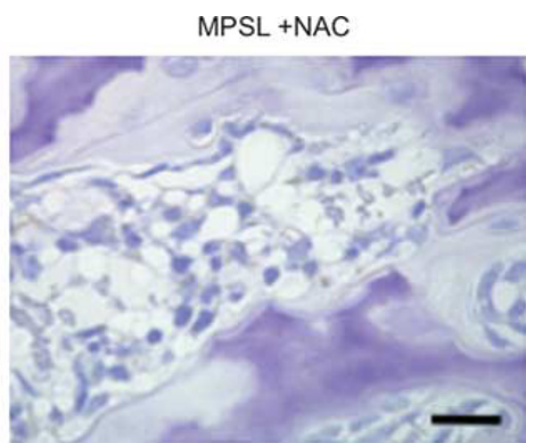
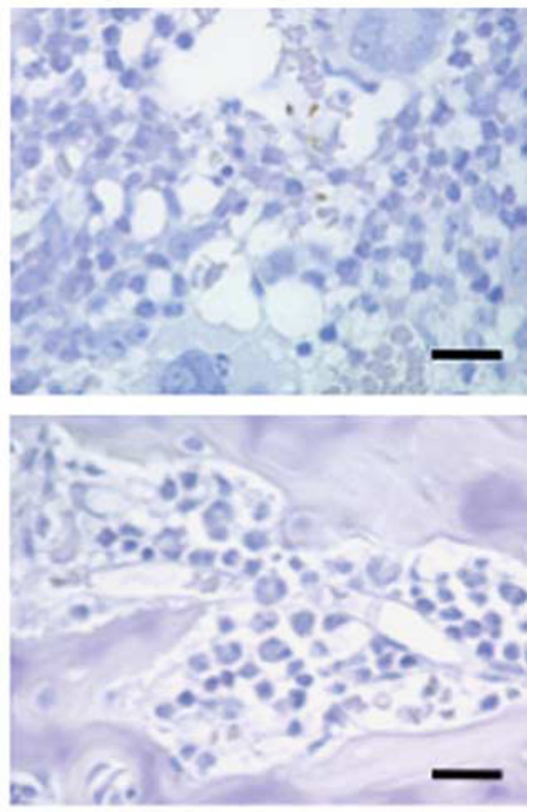
and was significantly increased by MPSL treatment $3 \mathrm{~h}$ after the last treatment (Figure 6b). Co-treatment of NAC with MPSL significantly decreased TRIM21 expression induced by MPSL. Viperin expression was observed in the nuclei of fat cells, and the levels of Viperin expression were significantly higher in the MPSL + NAC group when compared with the saline group (Figures $7 \mathrm{a}$ and $\mathrm{b}$ ). IFN- $\alpha$ expression was observed in osteoblasts and bone marrow cells and was significantly increased by NAC treatment at 12 and $24 \mathrm{~h}$ (Figures $8 \mathrm{a}$ and $\mathrm{b}$ ). These findings suggest that reductions in TRIM21 expression in the femoral head cause an accumulation of IFN- $\alpha$, which may be associated with the development of ONFH.

\section{DISCUSSION}

In this study, we found that co-treatment with corticosteroids and NAC exacerbate the development of $\mathrm{ONFH}$ in rats a
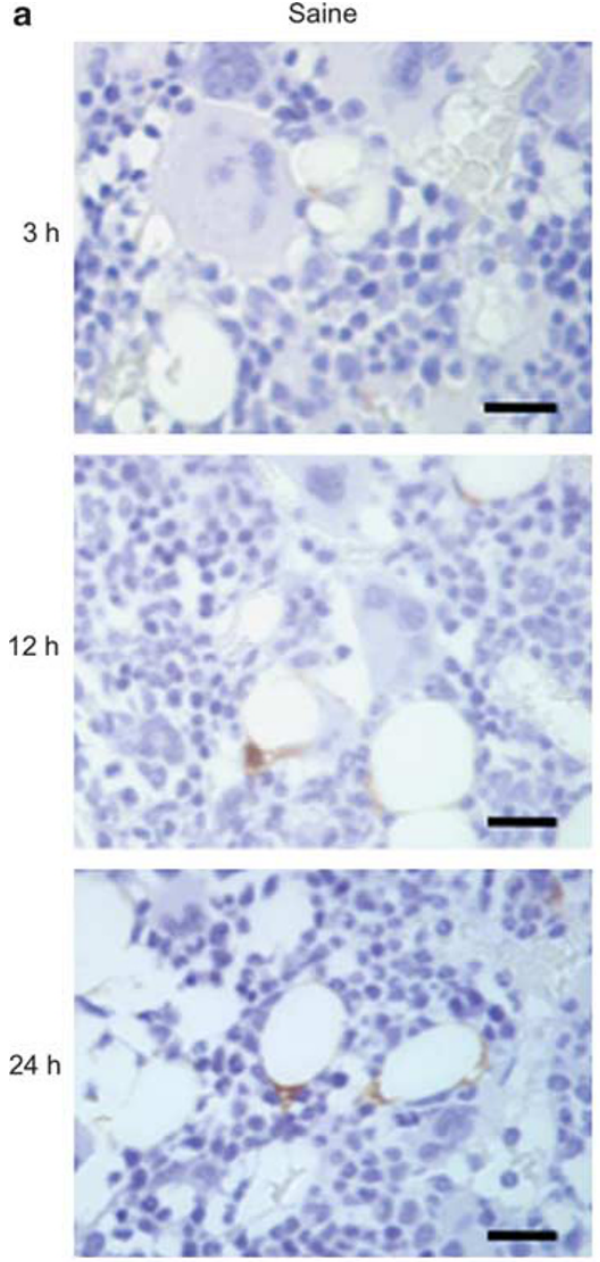

MPSL
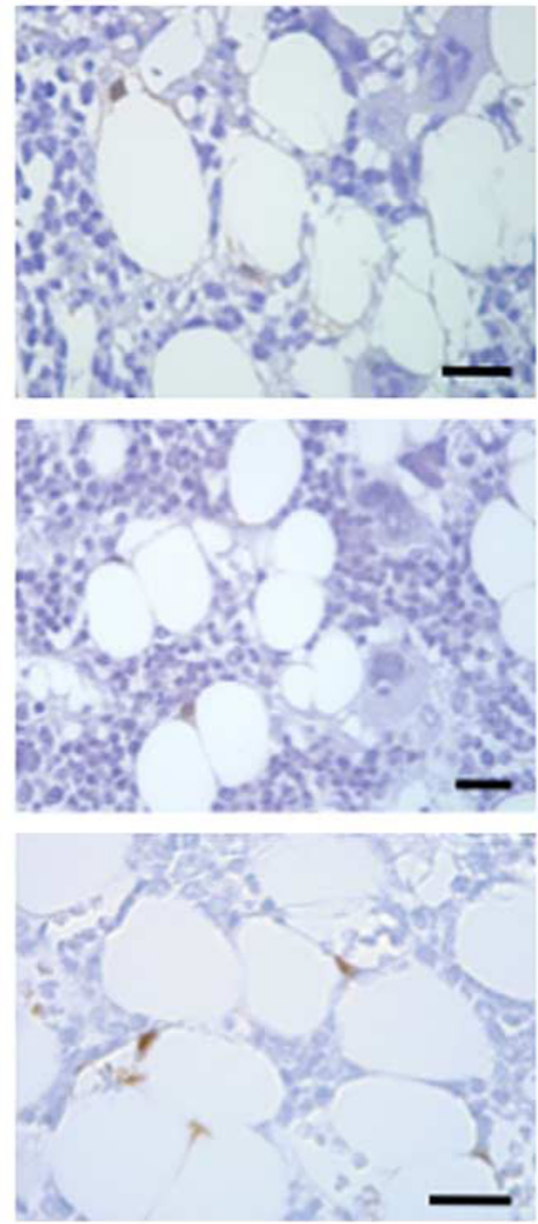

b ㅇำ

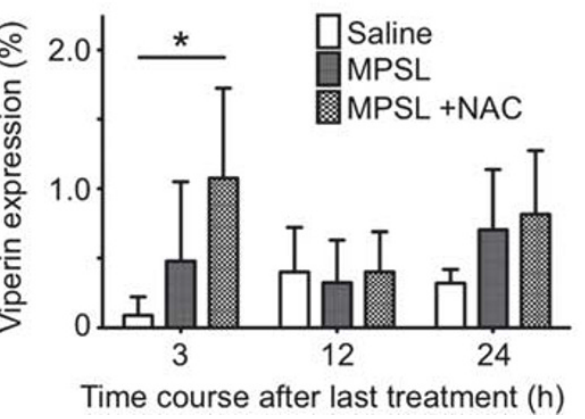

MPSL +NAC
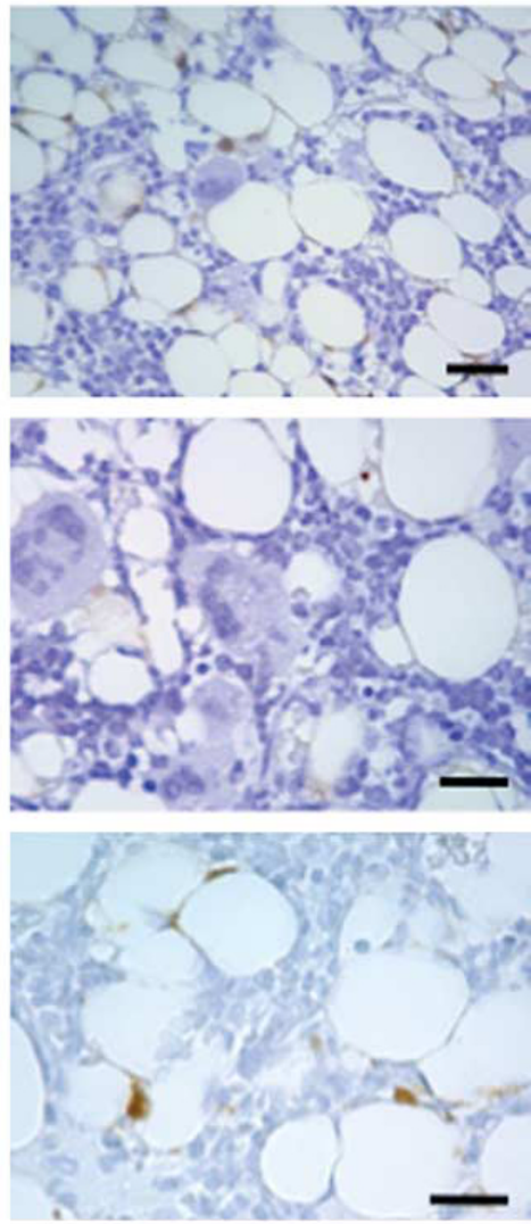

Figure 7 Immediate changes in Viperin in the femoral head. (a) Histopathological appearances of the femoral head after Viperin immunohistochemical staining 3, 12, and $24 \mathrm{~h}$ after the last treatment. Scale bar $=20 \mu \mathrm{m}$. (b) Quantitative analyses of Viperin expression in the femoral head are expressed as the percentage of the total counterstained tissue area that was stained for Viperin. There were no significant differences observed between the groups. Data show mean \pm s.d. $(n=3-4)$. 
following LPS injections. Corticosteroid treatment induced TRIM21 expression in the femoral head. However, co-treatment with NAC reduced the expression of TRIM21 and increased the levels of IFN $-\alpha$ in the femoral head. Because IFN- $\alpha$ is known to induce cell death, ${ }^{17}$ these findings suggest that reductions in TRIM21 and the accumulation of IFN- $\alpha$ may cause ONFH. In fact, patients with SLE and Sjögren's syndrome show autoantibodies against TRIM $21^{7,8}$ and increased plasma levels of IFN- $\alpha .^{5}$ Therefore, our observations in this animal model are analogous to clinical findings. The pathophysiological mechanisms underlying steroid-induced ONFH have been studied extensively and are thought to be multifactorial, but the pathogenesis of ONFH remains unclear. Previous studies have reported that hyperlipidemia, accumulation of fat cells in the bone marrow and enlargement of fat cells occur in rabbits with steroid-induced osteonecrosis, a

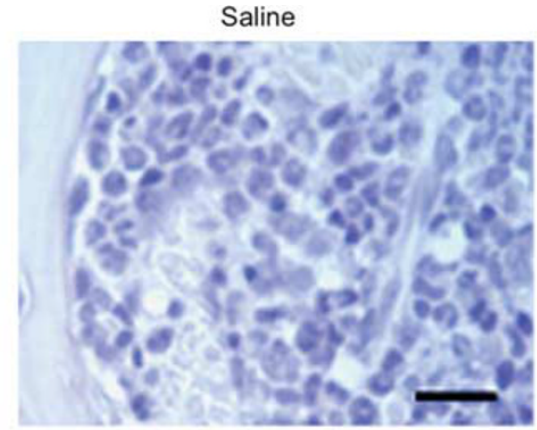

$12 \mathrm{~h}$

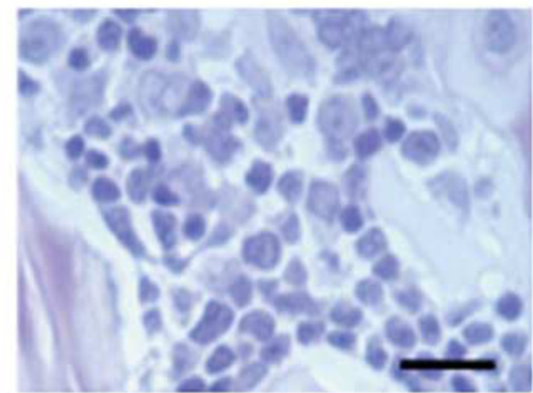

$24 \mathrm{~h}$

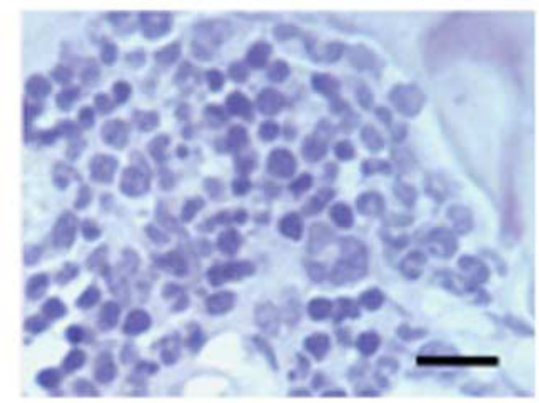

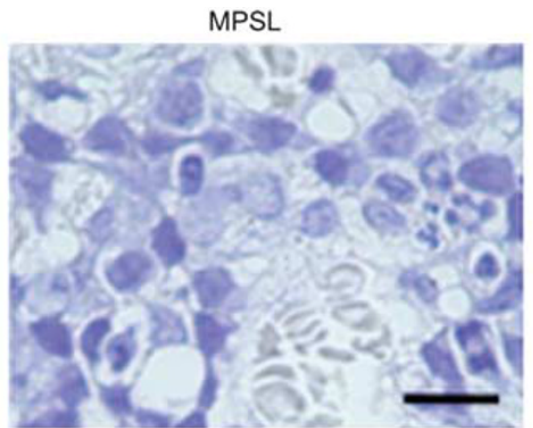
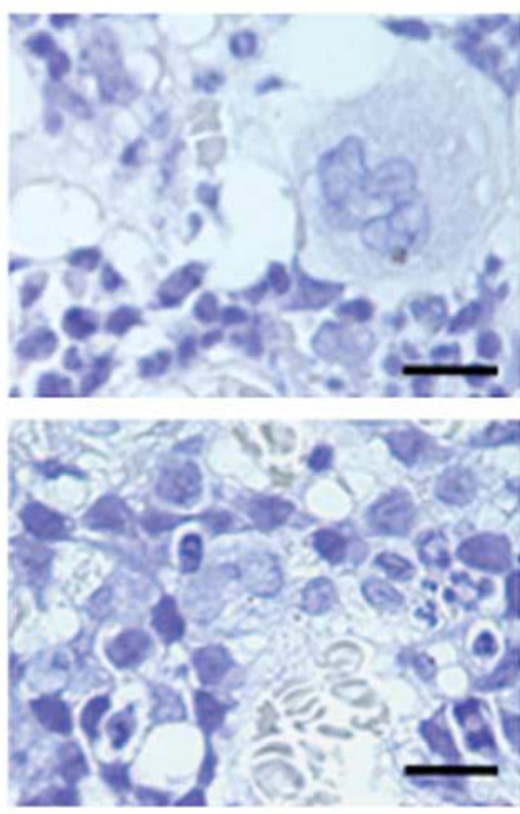

b

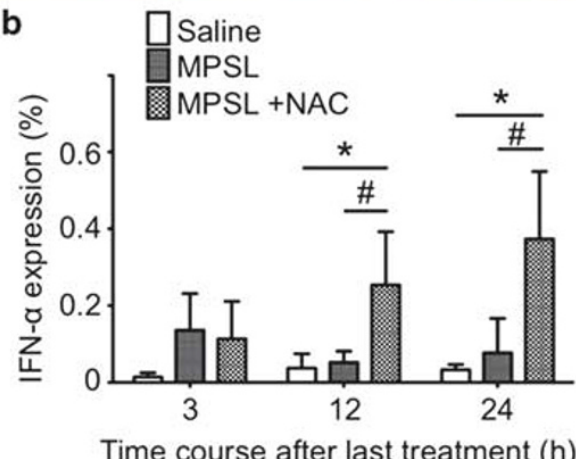

Time course after last treatment $(\mathrm{h})$
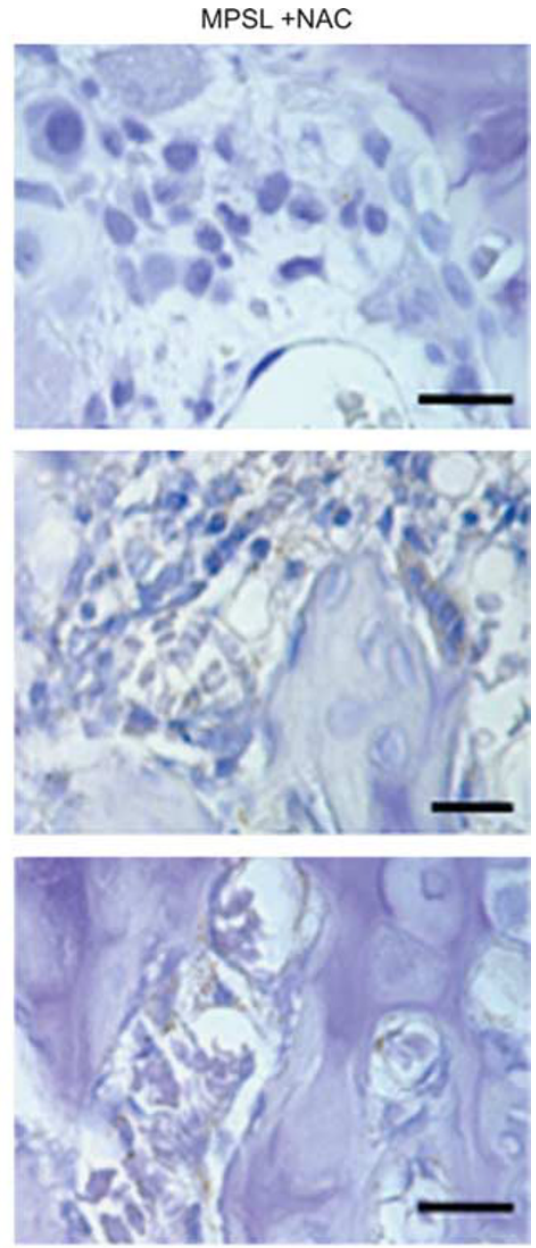

Figure 8 Immediate changes in IFN- $\alpha$ in the femoral head. (a) Histopathological appearance of the femoral head after IFN- $\alpha$ immunohistochemical staining 3,12, and $24 \mathrm{~h}$ after the last treatment. Scale bar $=20 \mu \mathrm{m}$. (b) Quantitative analyses of IFN- $\alpha$ in the femoral head were expressed as the percentage of the total counterstained tissue area that was stained for IFN- $\alpha$. Data show the mean \pm s.d. $(n=3-4)$. ${ }^{*} P<0.05$ vs the saline group, ${ }^{\#} P<0.05$ vs the MPSL group by two-way ANOVA with Bonferroni's post hoc test. 
results that suggest that abnormal lipid metabolism may be associated with the pathogenesis of ONFH. ${ }^{16,18}$ Recently, we reported an increased risk of ONFH in autoimmune disease patients showing no immediate increase in hepatic enzyme after steroid therapy. ${ }^{19}$ In the present study, corticosteroid treatment induced hyperlipidemia and fat cell accumulation in the femoral head of rats. However, there were no significant differences in fat cell accumulation or lipid metabolism in rats with ONFH and those without ONFH. Therefore, the abnormal lipid metabolism induced by corticosteroids may have a minimal impact on the pathogenesis of ONFH.

Simultaneous treatment with NAC and corticosteroids resulted in an increased development of ONFH following LPS injections. However, the administration of NAC after corticosteroid treatment did not increase the incidence of ONFH. These findings were contradictory to each other. LPS induces the activation of NF- $\kappa \mathrm{B}$ via TLR4 signaling. ${ }^{20} \mathrm{NAC}$ suppresses the activity of NF- $\kappa$ B induced by LPS. ${ }^{21,22}$ It has been reported that reactive oxidative species is a transmitter between TNF- $\alpha$ and NF- $\kappa$ B. ${ }^{23}$ Therefore, other antioxidants may cause the same effects as NAC. Corticosteroids interfere with the transcriptional activity of NF- $\kappa \mathrm{B} .{ }^{24,25}$ Indeed, our finding of reduced levels of circulating IL- $1 \beta$ suggests the inhibition of NF- $\kappa$ B (Figure 1c). Corticosteroid treatment significantly decreased NF- $\kappa \mathrm{B}$ activity in the spleen and liver immediately after treatment (Figures $2 \mathrm{~b}$ and c). Co-treatment with NAC and corticosteroids resulted in a prolonged inactivation of NF- $\kappa$ B in the spleen (Figure $2 b$ ). Recently, it has been reported that glucocorticoids suppress the nuclear translocation of IRF3 and the production of type I IFN induced by Poly (I:C), a ligand of TLR3, but do not alter the LPS-induced elevation of nuclear IRF3 or the enhancement of IFN- $\beta$ secretion by macrophages. ${ }^{26}$ In this study, the activity of IRF3 and IRF7 in the liver and the plasma levels of IFN- $\alpha$ were increased transiently $12 \mathrm{~h}$ after corticosteroid treatment, but co-treatment with NAC resulted in a suppression of plasma IFN- $\alpha$ levels (Figure 2). These findings suggest that an imbalance between the activity of NF- $\kappa \mathrm{B}$ and the activity of IRF3 and IRF7 occurs in response to corticosteroid treatment. We then focused on the potential role of TRIM21 in mediating this imbalance. NAC treatment decreased the expression of TRIM21 (Figures $4 \mathrm{~b}$ and 6) and increased the expression of IFN- $\alpha$ in the femoral head (Figure 8 ) when compared with corticosteroid alone. Yang et $a l^{27}$ reported that TRIM21 increases the stability of IRF3 and enhances the induction of type I IFN. In contrast, Higgs et $a l^{28}$ reported that TRIM21 interacts with IRF3 to promote the ubiquitination and degradation of IRF3 and limit IFN- $\alpha$ induction downstream of TLR3, TLR4, and RIG-I. It has also been reported that the expression of TRIM21 is inhibited by NAC in a concentration-dependent manner. ${ }^{29}$ In addition, we show here that the number of CD45R-expressing cells is decreased by corticosteroid treatment (Figure 4), which may result from the induction of IFN- $\alpha$. Viperin expression was significantly increased in the femoral bone marrow after cotreatment with NAC and corticosteroids when compared with the saline group (Figure 7). Viperin promoted the TLR7- and TLR9-mediated production of type I IFN by pDCs, ${ }^{12}$ a result that indicates that Viperin expression may induce IFN $-\alpha$. Therefore, these findings suggest that the induction of Viperin and the suppression of TRIM21 expression may cause the sequential augmentation of IFN- $\alpha$ expression, ultimately leading to the development of ONFH.

In conclusion, we found that simultaneous treatment of NAC and corticosteroid following LPS injections increases the development of ONFH in rats. This combined treatment immediately suppressed TRIM21 expression and subsequently induced IFN- $\alpha$ expression in the femoral head. These proteins may be potential novel targets for preventive manipulation.

Supplementary Information accompanies the paper on the Laboratory Investigation website (http://www.laboratoryinvestigation.org)

\section{ACKNOWLEDGEMENT}

This work was supported in part by the Grants-in-Aid for Scientific Research (B) $(H M, 20390196)$ and for Young Scientists (B) (SO, 22791390) of the Japanese Society for the Promotion of Science.

\section{DISCLOSURE/CONFLICT OF INTEREST}

The authors declare no conflict of interest.

1. Abeles M, Urman JD, Rothfield NF. Aseptic necrosis of bone in systemic lupus erythematosus. Relationship to corticosteroid therapy. Arch Intern Med 1978;138:750-754.

2. Mont MA, Jones LC, Hungerford DS. Nontraumatic osteonecrosis of the femoral head: ten years later. J Bone Joint Surg Am 2006;88:1117-1132.

3. Subramanian S, Tus $\mathrm{K}, \mathrm{Li} \mathrm{QZ}$, et al. A TIr7 translocation accelerates systemic autoimmunity in murine lupus. Proc Natl Acad Sci USA 2006;103:9970-9975.

4. Christensen SR, Shupe J, Nickerson K, et al. Toll-like receptor 7 and TLR9 dictate autoantibody specificity and have opposing inflammatory and regulatory roles in a murine model of lupus. Immunity 2006;25:417-428.

5. Kirou KA, Lee C, George S, et al. Coordinate overexpression of interferon-alpha-induced genes in systemic lupus erythematosus. Arthritis Rheum 2004;50:3958-3967.

6. Lee TP, Tang SJ, Wu MF, et al. Transgenic overexpression of antidouble-stranded DNA autoantibody and activation of Toll-like receptor 4 in mice induce severe systemic lupus erythematosus syndromes. J Autoimmun 2010;35:358-367.

7. Ben-Chetrit $E$, Chan EK, Sullivan KF, et al. A $52-k D$ protein is a novel component of the SS-A/Ro antigenic particle. J Exp Med 1988;167:1560-1571.

8. Billaut-Mulot O, Cocude C, Kolesnitchenko V, et al. SS-56, a novel cellular target of autoantibody responses in Sjogren syndrome and systemic lupus erythematosus. J Clin Invest 2001;108:861-869.

9. Espinosa A, Hennig J, Ambrosi A, et al. Anti-Ro52 autoantibodies from patients with Sjogren's syndrome inhibit the E3 ligase activity of Ro52 by blocking the E3:E2 interface. J Biol Chem 2011;286:36478-36491.

10. Wada K, Niida $M$, Tanaka $M$, et al. Ro52-mediated monoubiquitination of IKK $\beta$ down-regulates NF- $\kappa B$ signalling. J Biochem 2009;146: 821-832.

11. Higgs R, Lazzari E, Wynne C, et al. Self protection from anti-viral responses-Ro52 promotes degradation of the transcription factor IRF7 downstream of the viral Toll-Like receptors. PLoS One 2010;5:e11776.

12. Saitoh $\mathrm{T}$, Satoh $\mathrm{T}$, Yamamoto $\mathrm{N}$, et al. Antiviral protein Viperin promotes Toll-like receptor 7- and Toll-like receptor 9-mediated type I 
interferon production in plasmacytoid dendritic cells. Immunity 2011;34:352-363.

13. Okazaki S, Nishitani Y, Nagoya S, et al. Femoral head osteonecrosis can be caused by disruption of the systemic immune response via the tolllike receptor 4 signalling pathway. Rheumatology (Oxford). [Research Support, Non-US Gov't] 2009;48:227-232.

14. Nishitani $\mathrm{Y}$, Matsumoto $\mathrm{H}$. Ethanol rapidly causes activation of JNK associated with ER stress under inhibition of ADH. FEBS Lett [Research Support, Non-US Gov't] 2006;580:9-14.

15. Katada $R$, Nishitani $Y$, Honmou $O$, et al. Prior ethanol injection promotes brain edema after traumatic brain injury. J Neurotrauma 2009;26:2015-2025

16. Yamamoto T, Irisa $\mathrm{T}$, Sugioka $\mathrm{Y}$, et al. Effects of pulse methylprednisolone on bone and marrow tissues: corticosteroidinduced osteonecrosis in rabbits. Arthritis Rheum 1997;40:2055-2064.

17. Nanbo A, Inoue K, Adachi-Takasawa K, et al. Epstein-Barr virus RNA confers resistance to interferon-alpha-induced apoptosis in Burkitt's lymphoma. EMBO J 2002;21:954-965.

18. Kabata T, Kubo T, Matsumoto $\mathrm{T}$, et al. Onset of steroid-induced osteonecrosis in rabbits and its relationship to hyperlipaemia and increased free fatty acids. Rheumatology (Oxford) 2005;44: 1233-1237.

19. Okazaki S, Nagoya S, Yamamoto M, et al. High risk of osteonecrosis of the femoral head in autoimmune disease patients showing no immediate increase in hepatic enzyme under steroid therapy. Rheumatol Int 2012; doi:10.1007/s00296-011-2295-y.

20. Kawai T, Akira S. Toll-like receptors and their crosstalk with other innate receptors in infection and immunity. Immunity 2011;34: $637-650$.
21. Asehnoune $K$, Strassheim $D$, Mitra $S$, et al. Involvement of reactive oxygen species in Toll-like receptor 4-dependent activation of NFkappa B. J Immunol 2004;172:2522-2529.

22. Oka S, Kamata H, Kamata K, et al. N-acetylcysteine suppresses TNFinduced NF-kappaB activation through inhibition of IkappaB kinases. FEBS Lett 2000;472:196-202.

23. Kamata $\mathrm{H}$, Honda $\mathrm{S}$, Maeda $\mathrm{S}$, et al. Reactive oxygen species promote TNFalpha-induced death and sustained JNK activation by inhibiting MAP kinase phosphatases. Cell 2005;120:649-661.

24. Auphan N, DiDonato JA, Rosette $C$, et al. Immunosuppression by glucocorticoids: inhibition of NF-kappa B activity through induction of I kappa B synthesis. Science 1995;270:286-290.

25. Scheinman Rl, Cogswell PC, Lofquist AK, et al. Role of transcriptional activation of I kappa B alpha in mediation of immunosuppression by glucocorticoids. Science 1995;270:283-286.

26. Bhattacharyya S, Zhao Y, Kay TW, et al. Glucocorticoids target suppressor of cytokine signaling 1 (SOCS1) and type 1 interferons to regulate Toll-like receptor-induced STAT1 activation. Proc Natl Acad Sci USA 2011;108:9554-9559.

27. Yang $\mathrm{K}$, Shi $\mathrm{HX}$, Liu XY, et al. TRIM21 is essential to sustain IFN regulatory factor 3 activation during antiviral response. J Immunol 2009; 182:3782-3792.

28. Higgs R, Ni Gabhann J, Ben Larbi N, et al. The E3 ubiquitin ligase Ro52 negatively regulates IFN-beta production post-pathogen recognition by polyubiquitin-mediated degradation of IRF3. J Immuno 2008;181:1780-1786.

29. Saegusa J, Kawano S, Koshiba M, et al. Oxidative stress mediates cell surface expression of SS-A/Ro antigen on keratinocytes. Free Radic Biol Med 2002;32:1006-1016. 